\title{
High frequency of low noise amplifier architecture for WiMAX application: A review
}

\author{
Abu Bakar Ibrahim, Che Zalina Zulkifli, Shamsul Arrieya Ariffin, Nurul Husna Kahar \\ Department of Computing, Faculty of Art, Computing and Creative Industry Universiti Pendidikan Sultan Idris, \\ Tanjong Malim, Malaysia
}

\begin{abstract}
Article Info
Article history:

Received Apr 29, 2020

Revised Jul 23, 2020

Accepted Oct 12, 2020

Keywords:

Low noise amplifier

Noise figure

WiMAX

ABSTRACT

The low noise amplifier (LNA) circuit is exceptionally imperative as it promotes and initializes general execution performance and quality of the mobile communication system. LNA's design in radio frequency (R.F.) circuit requires the trade-off numerous imperative features' including gain, noise figure (N.F.), bandwidth, stability, sensitivity, power consumption, and complexity. Improvements to the LNA's overall performance should be made to fulfil the worldwide interoperability for microwave access (WiMAX) specifications' prerequisites. The development of front-end receiver, particularly the LNA, is genuinely pivotal for long-distance communications up to $50 \mathrm{~km}$ for a particular system with particular requirements. The LNA architecture has recently been designed to concentrate on a single transistor, cascode, or cascade constrained in gain, bandwidth, and noise figure.
\end{abstract}

Wireless

This is an open access article under the CC BY-SA license.

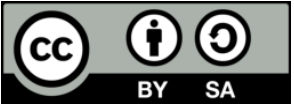

\section{Corresponding Author:}

Abu Bakar Ibrahim

Department of Computing

Faculty of Art, Computing and Creative Industry

Universiti Pendidikan Sultan Idris

35900 Tanjung Malim

Email: bakar@fskik.upsi.edu.my

\section{INTRODUCTION}

In the industrial revolution 4.0 (IR4.0) Era, the demand for wireless communication systems has grown. Numerous wireless communication technologies exist in a distinctive recurrence band for diverse applications based on the consumers' demands. Because of the high transmission speed (70 Mbps) and lengthy-distance transmission (50 kilometers), the WiMAX was indeed a technological breakthrough for wireless communication as one of appealing technology. Multiple bands such as $2.3-2.7 \mathrm{GHz}, 3.4-3.6 \mathrm{GHz}$, also 5.1-5.8 GHz in this system have used the transmittance of information according to the IEEE 802.16 specification. [1] stressed that is one of the drawbacks in R.F receiver is the design of LNA front-end configuration as the satisfactory LNA ought to fulfil excellent impedance input matching, adequate power gain, and low noise figure in the same desired range.

WiMAX was implemented by offering improved bandwidth and better inscribe to strengthen the wireless LAN (1EEE 802.11a) standard. With the scope of ranges extending up to 50 kilometers radius, WiMAX allowing broadband services to be accommodated to a range of clients includes residential home, small and medium-sized enterprises (SME), large enterprises in an urban, conservative area and rural districts without requiring direct sightline. Regardless, WiMAX initiates not to outplace the wireless LAN. The WiMAX application is envisioned to interconnect the IEEE 802.11a hotspots and interface with the internet. In WiMAX, the orthogonal frequency division multiplexing (OFDM) allows high Internet connectivity data rates up to $70 \mathrm{Mbps}$. Also, WiMAX enables the wireless mesh network to be more stable 
and efficient by applying OFDM and scheduled MAC. WiMAX is outlined to function anyplace within a 2-6 GHz range fitting accessible spectrum. The range may be authorized, or unlicensed depends on its area and host country [2].

In a flash, the wireless communication system has been one of the fastest-developing sectors in the industry of communications. [3] Stated that the fundamentals encouragements in arrears the advent of various generations of wireless systems of communication such as expanding data rates, escalating coverage area, and discoverable parts in the same chip. The modern communications system was based on R.F transmission are one of the most notable cases of this challenging request as the systems existing utilized in the way of life. For example, mobile phones, wireless sensors, a laptop which are required expanding flexibility and capacity to store information, massive transmittance rates of data and reduction in size. In addition to the dramatic size reduction of electronic parts, more sophisticated equipment is required in conjunction with a more prominent number of service accessibility in single equipment (ideally portable), which involves unused material to optimize the features provided. The receiver architecture is one of the most significant parts of the R.F system. There is an LNA that plays an essential role in the receiver system's execution and affectability.

R.F transceiver systems break the bonds of wired connexion between a partitioned building and WiMAX, particularly in the range in which it is inconceivable to engage the wired bridge. The wireless technology of WiMAX is cost-effective yet systematic compared with the installation of wired networks. Introduced in IEEE 802.16 WiMAX, the latest OFDM contributes a high-rise of data rates up to $70 \mathrm{Mbps}$ [4]. Adapting the baseband sign from the transmitted R.F. signal portrayed the R.F. receiver in WiMAX lead in allowing the device to communicate wirelessly. As a consequence, the efficiency of the WiMAX system depends on the well-outlined of the R.F front-end receiver system, reducing the level of noise or distortions within the system [5].

Broadband wireless lies at converting the two most astonishing development storeys of the telecom sector in over the recent years. Wireless and broadband are exceptional, promptly delighted in marketable selection. In 1990, mobile wireless networks expanded to over 5000 million in 2010, from 11 million worldwide subscribers [6]. In the same time, the internet has grown from an inquisitive academic instrument to about around a billion subscribers. This stunning development is driven by the need for higher-speed internet connection services that contribute to increasing the adoption of broadband simultaneously. Broadband subscriptions worldwide have risen essentially from nearly zero to over 2000 million in less than a decade.

Prevalent mass-market broadband access technologies nowadays are digital subscriber line (DSL) tech that conveys broadband through double pair of phone wires and cable modem technology that distributes via coax cable T.V. Each technology usually satisfies each user with data of up to a few megabits per second and proceeds to numerous of $10 \mathrm{Mb}$ per second. These services have been growing tremendously ever since its first launch in the late 1990s. About 50 million broadband subscribers, respectively, and over $50 \%$ of home internet users are in the United States. This number reflects more than 50 million internet users worldwide in 2019, as seen in Figure 1 [6].

Internet usage keeps growing, but barriers lie ahead

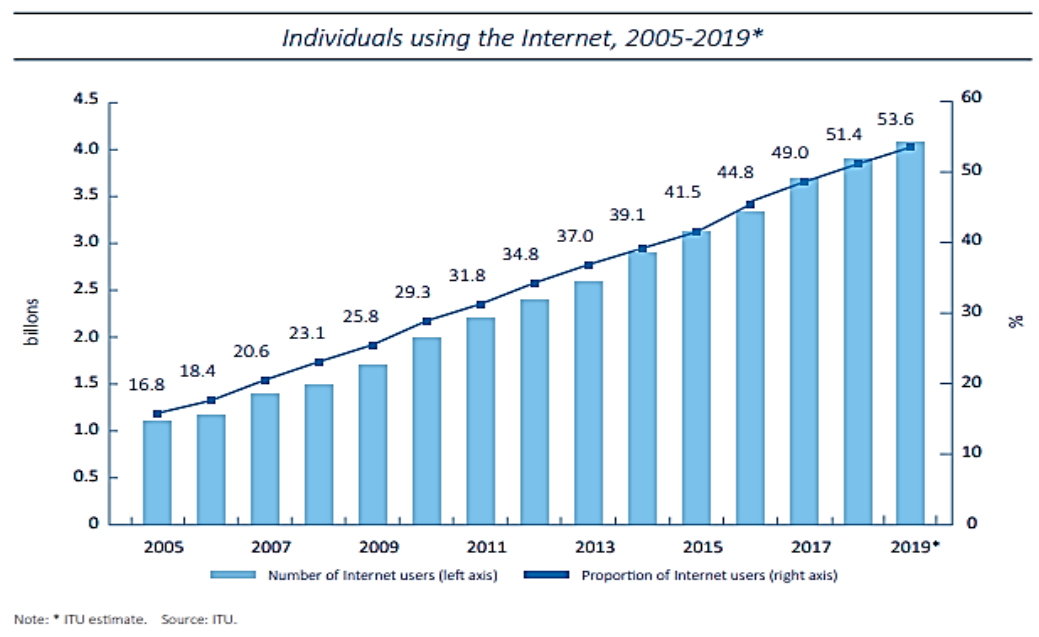

Figure 1. Global numbers of internet user in years 2005-2019 [6] 
A wireless broadband telecommunication system for metropolitan areas is WiMAX. In other words, the WiMAX goal is to supply 50 kilometers of high-speed wireless communication over the long distances within the Mbps range. The two standard sets are 802.16-2004 (802.16d) for fixed WiMAX, and for mobile WiMAX 802.16-2005(802.16e) are 802.16. The wireless broadband of WiMAX standard connection offers the lost last-mile connexion in the metropolis where DSL, cable, as well as other broadband connection techniques, is inaccessible or costly. The WiMAX also satisfies the rural area's option to satellite internet services and enables customer facilities [7].

Specifications of IEEE 802.16 affect the air interface between the transceiver station of a subscriber and the base station of the transceiver. In June 2004, the IEEE accepted a fixed WiMAX of IEEE 802.162004 standard (so-called 802.16d) offering a fixed, point-to-multi-point wireless broadband operation service and using the fast Fourier transform (OFDM 256-FFT) for its product profile. Both time division duplex (FDD) and frequency are enabled by fixed WiMAX 802.16-2004.

The IEEE affirmed the mobile WiMAX 802.16-2005 standard (known as 802.16e) in December 2005. The mobility features have been added in WiMAX between $2-11 \mathrm{GHz}$ of licensed bands based on previous IEEE 802 standard.16e. The WiMAX 802.16e enables fixed wireless as well as mobile non-line of sight (NLOS) apps by strengthening OFDMA. The IEEE 802.16 with WiMAX is built as a free of charge Wi-Fi and Bluetooth application. The quick comparison of fixed and mobile (802.16) with WLAN (802.11) and Bluetooth (802.15.1) as demonstrated in Table 1.

Table 1. Comparison between WiMAX, WLAN and Bluetooth

\begin{tabular}{ccccc}
\hline Parameters & $\begin{array}{c}\text { IEEE802.16d } \\
\text { (Fixed WiMAX) }\end{array}$ & $\begin{array}{c}\text { IEEE802.16e } \\
\text { (Mobile WiMAX) }\end{array}$ & $\begin{array}{c}802.11 \\
\text { (WLAN) }\end{array}$ & $\begin{array}{c}802.15 \\
\text { (Bluetooth) }\end{array}$ \\
\hline Frequency Band & $2-66 \mathrm{GHz}$ & $2-11 \mathrm{GHz}$ & $2.4 \mathrm{GHz}$ & Varies \\
Range & $50 \mathrm{~km}$ & $10 \mathrm{~km}$ & $100 \mathrm{~m}$ & $10 \mathrm{~m}$ \\
Data transfer rate & $134 \mathrm{Mbps}$ & $15 \mathrm{Mbps}$ & $11-55 \mathrm{Mbps}$ & $20-55 \mathrm{Mbps}$ \\
Number of users & Thousands & Thousands & Dozens & Dozens \\
\hline
\end{tabular}

WiMAX is an emerging technology as the roam in between WiMAX with WLAN standard needs to assimilate cheap twofold-mode receivers to allow mobile users' impeccable communication. In [8, 9] reported the IEEE 802.11a WLAN to perform in $5 \mathrm{GHz}$ based on OFDM according to the unlicensed national information infrastructure (UNII) band.

\section{THE RECEIVER ARCHITECTURES REVIEW}

The receiver design in which the LNA resided is crucial to identify and understand. Architectural merits and issues considered during the LNA design process. The wireless standard which is applied for the LNA is equally essential, as the specification imposed by the standard is the benchmark of LNA performance. In recent decades, wireless communication is becoming very famous because it has influenced the trend in transceiver designs. The focus of modern receiver designs is to increase the integration level of R.F. and mixed-mode circuitries. The next step is to develop "single-chip radios". Numerous of receiver architectures, such as superheterodyne receiver, were still very popular in radio designs. The directconversion receiver (DCR) and its spin-off such as the Low-IF, are available.

In $[10,11]$ emphasized that the wideband-IF receiver is another architecture worth noting. The use of the receiver architecture of DCR to achieve full circuit integration on the chip seems to be the best option. These are because the present portable and wireless technology transceiver design plays an essential role in full circuit integration as this is how various radio standards can be implemented in a single radio. Besides, full integration would lead to smaller radio sizes and thus greater portability. According to [12], the design of DCR is less complicated and smaller because there are few blocks and multiple of IF are eliminated to lower the cost of power and fabrication compared with superheterodyne.

The LNA for the WiMAX application is designed for this research. The LNA has to reside in a DCR environment because of the DCR's capabilities and growing popularity. During the development phase, all matters about the DCR must be put into consideration. Nevertheless, [13] emphasized that the WiMAX 802.16d standard requirement is vital to be understood since this will formed the LNA's design goal.

\section{RADIO FREQUENCY (R.F.) FRONT-END RECEIVER}

The R.F. front-end receiver's primary function is to enhance the antenna's carrier signal, downconvert the signal, choose the preferred channel, and finally extract the carrier's baseband information. The LNA is located in the receiver chain after the antenna at the first stage. It is amongst the most important

High frequency of low noise amplifier architecture for WiMAX application: A review (Abu Bakar Ibrahim) 
aspects that provide adequate gain while at the same time reducing noise. The typical basic building blocks of the R.F. front-end receiver are shown in Figure 2.

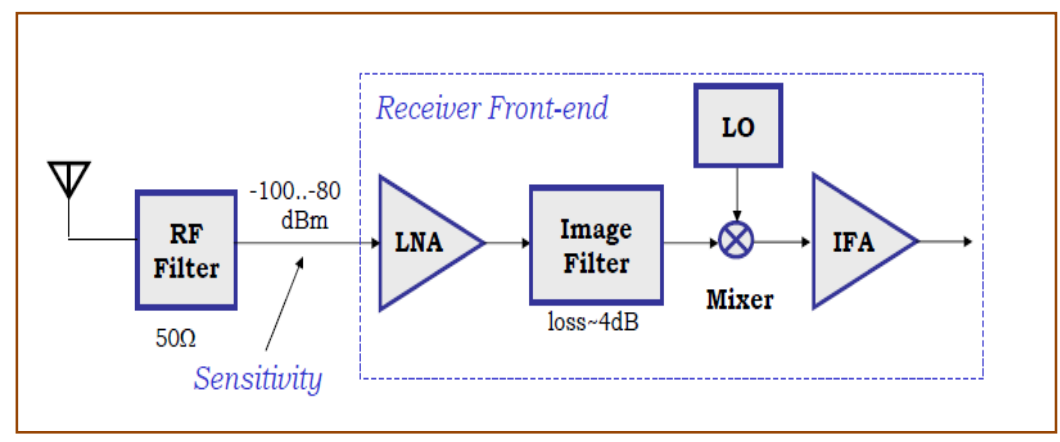

Figure 2. Block diagram of a basic R.F. front-end receiver

LNA was an essential section of the overall receiver system by providing the requisite amplifier gain whilst adding minimum noise to reach the needed signal-to-noise ratio (SNR) before the baseband signal was processed. An LNA, image filter, local oscillator (L.O.), intermediate frequency amplifier (IFA), and mixer are part of a typical R.F front-end. The primary feature of LNA is to have sufficiently high gain in overcoming the noise of subsequent phases such as the mixer while adding the lowest possible noise. Without triggering intermodulation distortions, it ought to be linear enough to manage substantial interference. The LNA followed by a mixer that converts down to the intermediate frequency (IF) determined by the L.O. Finally, after the required filtering has been carried out by the mixer, another down-conversion and filtering step is taken before the signal can be amplified and ready for Analog-to-Digital Conversion (ADC). Performance of the receiver depends on the working environment, design of the system and the design of the circuit. The permissible noise and distortion level varies depending on the application where noise and distortion specify a lower limit on the output's usable signal level. The signal power must be larger than the noise power by the amount specified by the required SNR for the output signal to be useful. The noise and distortion would need to be at least the minimal signal-to-noise and distortion ratio (SNDR) specified below the signal power, which included the distortion generated in the receiver [14].

\section{LOW NOISE AMPLIFIER REVIEW}

LNA's front-end receiver is the essential part of the receiver because it determines its overall performance. Identifying a suitable design and topology for the LNA is crucial because it is supposed to provide high input/output isolation, low noise, high gain, and wideband. [14] has demonstrated the development of LNA for WiMAX 802.16a standard with an ASM 0.35 um CMOS process which is developed to shelter the range of the frequency for licensed and unlicensed WiMAX 2.3-5.9 GHz bands. A wideband input and output match of S11 and S22 is achieved by the amplificatory, which is less than $10 \mathrm{~dB}$, a flat gain of $13 \mathrm{~dB}$, and an estimated $3 \mathrm{~dB}$ noise figure for the whole band top to higher frequencies. It demonstrated the LNA wideband, which employed an input matching of Chebychev filter and output matching inductive shunt feedback with $25 \mathrm{~mA}$ and $2.5 \mathrm{~V}$ electric supply bias current. The gain of the amplifier is low compare to the required IEEE 802.16 standard $(30 \mathrm{~dB})$. For a sampling amplifier, the noise figure is at $3 \mathrm{~dB}$.

In [15] stated that a miniature distributed LNA design for applications of ultra-wideband. The three stages distributed amplifier occupied a die-area of 288 X $291 \mu \mathrm{m}$ which made it the smallest distributed amp recorded. They reported the LNA overall gain reaches a flat gain of $6 \mathrm{~dB}$ and a $5 \mathrm{~dB}$ noise for frequency range 3.1-10.9 GHz. The overall efficiency of these findings should be improved in the context of gain and noise.

A 1 V $5 \mathrm{GHz}$ CMOS feedback-front-end multiple-magnetic receiver designs suitable for lowvoltage operation have been reported by [16]. A single amplifier transistor is designed to reach high gain and reverse isolation using multiple magnetic feedbacks simultaneously. The feedback is based on three inductor transformers. For increasing reverse isolation of the LNA, the inductive degeneration of inductors is used. The receiver gain achieves $22.3 \mathrm{~dB}$, a $2.64 \mathrm{~dB}$ noise figure, and $50 \mathrm{MHz}$ bandwidth. The operating frequency of the system is $5 \mathrm{GHz}$. Overall performances for this research are excellent and acceptable. The feedback techniques provided high gain and also very little of low noise figure, but the bandwidth needs to be improved. 
A low voltage LNA developed using $0.35 \mu \mathrm{m}$ SiGe BiCMOS process, which was presented by [17]. This amplifier operated at the $5.8 \mathrm{GHz}$ centre frequency with a $1.2 \mathrm{~V}$ voltage source, and an energy gain of $12.1 \mathrm{~dB}$ at $5.8 \mathrm{GHz}$ with a low energy usage of $3.8 \mathrm{~mW}$ was achieved included all the biasing circuits. The total LNA noise figure is $3 \mathrm{~dB}$ with input/output impedance matching to $50 \Omega$. The single amplifier's gain is low compared to the required WiMAX at $50 \mathrm{~dB}$ - this system suitable for the mobile system and not to fix the WiMAX standard.

Her et al. [18] have identified an amplifier with low noise for standard WiMAX (802.16e) with TSMC $0.18 \mu \mathrm{m}$ RF CMOS process. The circuit is built with two-stage cascode LNA structures with fully integrated 2-6 GHz, using resistive shunt-feedback and simplifying the band-pass filter circuit to reach broad matching of the impedances input. The gain stage amp uses the cascode structure for the amplifier phase implementation. The input return loss $\mathrm{S}_{11}$ measurement is below $-10.9 \mathrm{~dB}$ over the range of 2-6 GHz. $\mathrm{S}_{21}$ was reached at $16.4 \mathrm{~dB}$ maximum power gain, and the minimal noise level was $4.1 \mathrm{~dB}$ for 2-6 GHz. The compression efficiency of $1 \mathrm{~dB}$ gain is approximately $-15 \mathrm{dBm}$ on the first and second circuit phase. The bias currents are $8.54 \mathrm{~mA}$ and $4.15 \mathrm{~mA}$ respectively, powered by a $1.1 \mathrm{~V}$ supply and $14.5 \mathrm{~mW}$ of the total power usage. The die size of all the pads is $1.32 * 1.21 \mathrm{~mm}^{2}$. The noise figure for this research needs to be optimized to fulfil the requirement of the WiMAX standard. Even though two stages cascaded amplifiers were developed, the achieve gain is not double. The research focused on low the consumption of the power and did not best performance on gain and noise figure.

Ultra-Wideband CMOS LNA single-stage was identified by [19]. It uses an inter-stage matching inductor for conventional inductive source structure cascode. The CMOS technology has been applied at $0.18 \mu \mathrm{m}$ with an ultra-wideband $3-5 \mathrm{GHz}$ system. The inter-stage inductor would increase overall of the broadband gain through careful optimization while attempting to maintain the amplifier's low noise level. The assembled prototype has an $\mathrm{S}_{21}$ energy gain of $12.7 \mathrm{~dB}, \mathrm{~S}_{11}$ input return loss of $-18 \mathrm{~dB}, \mathrm{~S}_{22}$ output return loss of $-3 \mathrm{~dB}, \mathrm{~S}_{12}$ contrary isolation of $-35 \mathrm{~dB}, 4.5 \mathrm{~dB}$ noise figure, and $4 \mathrm{GHz}$ IP3 input of $1 \mathrm{dBm}$ at the meantime utilizing $17 \mathrm{~mW}$ of D.C. dissipation at a $1.8 \mathrm{~V}$ voltage supply. Noise figure and gain for this research need to be improved. The recorded return loss in output is approximately $-10 \mathrm{~dB}$. This research focuses on optimizing the inductor for maintaining high gain. The gain reported for the cascaded amplifier is low compared to the required WiMAX standard.

Park designed and fabricated a fully integrated CMOS wideband LNA functioning over $2.3-7 \mathrm{GHz}$ using the $0.18 \mu \mathrm{m}$ CMOS process [20]. This configuration is the common source-common source (CS-CS) with doubling condenser cascode amp. With concurrent noise and input matching and low power consumption, it shows both low power decreases in load resistance $\left(\mathrm{R}_{\text {load }}\right)$ and high gain over 2.3-7 GHz. Simulation and measuring check the design technique and efficiency of wideband LNA. This LNA wideband reaches an average $S_{21}$ gain of $16.5 \mathrm{~dB}$, an $S_{11}$ input return loss of less than $-8 \mathrm{~dB}$, a 3.4-6.7 dB noise figure, and an IIP3 of $-7.5-3 \mathrm{dBm}$ at $2.3-7 \mathrm{GHz}$ with an energy usage of $10.8 \mathrm{~mW}$ below $1.8 \mathrm{~V}$ VDD. This research tried to improve the amplifier's bandwidth but used a resistive load to increase the noise figure. However, a noise figure should be enhanced by reducing the resistive element's use in the circuit.

In [21] has been clarified the ultra-compact resistive LNA feedback as an economical alternative to multiple the LNA wideband utilizing high-Q inductors for the several-band wireless applications. LNA resistive $12 \mathrm{~mW}$ feedback was seen with a $21 \mathrm{~dB}$ gain and a noise figure of $2.6 \mathrm{~dB}$ at $5 \mathrm{GHz}$, based on current reuse boost in trans-conductance. This LNA design is ideal for minimal-cost, multi-standard wireless front-end through the mixture of small die area, wide bandwidth, and moderate energy usage. A cascaded and cascaded transistor LNA with a new trans-conductance reuse improvement has been presented. The trade-off for this design is to maintain a modest gain throughout the frequency range and reduce each stage's nonlinearities that the LNA achieves. However, the output gain of $12.3 \mathrm{~dB}$ from a single-stage achieved is still lower than the targeted value. Implementation of the LNA in wireless frond-end requires 3 high-Q inductors to achieve input impedance, high gain, and low noise level. Utilize the area for intensive LNAs cascaded, however, has become increasingly costly, contributing to the demand for alternative implementation of LNA. The gain is low, and the noise figure is relatively high.

An LNA with a low pass filter at $5.6 \mathrm{GHz}$ for the receiver subsystem was reported [22]. The reported LNA gain achieved was $17.1 \mathrm{~dB}$ and $8.7 \mathrm{~dB}$ of noise level while the power was dissipated at $19.4 \mathrm{~mW}$. The challenge of this research was to sustain the supplying voltage under $0.5 \mathrm{~V}$. The return loss of simulated and measured input reflections exceeded less than -10dB over the exciting band. The LNA source inductor as well as the electromagnetic simulation showed that the inductance is $0.2 \mathrm{nH}$. The input impedance measurement, however, has had a smaller actual portion than the results of the simulation. It was showing that the inductor of the source may be underestimated. The characteristic impedance of LNA was designed with $50 \Omega$, but the termination port measured was not $50 \Omega$ showing imbalance had occurred. Besides, as reported, the complex impedance causes unwanted phase shift and severe phase imbalanced. The LNA used an LC-folded cascade configuration obtained desirable reverse isolation without increasing the

High frequency of low noise amplifier architecture for WiMAX application: A review (Abu Bakar Ibrahim) 
stacked transistor. The simulated and measured stage imbalances for this LNA were at a frequency under $5.4 \mathrm{GHz}$ due to low impedance matching technique. As it affected considerable degradation of the SNR, the output is indeed a concern. To avoid using a resistive matching network, the noise figure for this amplifier could be strengthened. However, the amplifier's bandwidth does not comply with WiMAX.

In [23] has stated that the wholly integrated $5.5 \mathrm{GHz}$ high-linearity LNA using a $0.18 \mathrm{~mm}$ R.F CMOS technology post-linearization method. This tactic implements an extra folded diode through a parallel R.C. circuit as an intermodulation distortion (IMD) sinker. They argue that they do not achieve high linearity, but that the gain degradation, power usage, including the noise level, was also reduced. LNA reaches an IIP3 of $8.33 \mathrm{dBm}$ input, a $10.02 \mathrm{~dB}$ energy gain, and a $3.05 \mathrm{~dB}$ noise at $5.5 \mathrm{GHz}$ biased at $6 \mathrm{~mA}$ from a $1.8 \mathrm{~V}$ power source. This research using the R.C. element, which the noise figure increase, and again achieves $10.02 \mathrm{~dB}$ is still low.

In [24] has presented the LNA's design intended for the applications of WiMAX. A cascaded common-source amplifier, a folded cascode amplifier, and a shunt feedback amplifier are the three LNA topologies that have been implemented. The amplifiers were driven by $1-\mathrm{V}$ supply voltage in a standard 90-nm CMOS process. Measurements of LNA were made for parameters such as i) energy gain, ii) noise level, iii) input matching, iv) output matching, v) contrary isolation, vi) stability, and vii) linearity. Rely on the utilization of figure-of-merit; the cascaded common-source LNA was obtained among the three with a simulated gain of $13.8 \mathrm{~dB}$ as well as a noise figure of $1.7 \mathrm{~dB}$ is similar to the works formerly released. These topologies achieve the simulated gain is low compare to the required of $30 \mathrm{~dB}$.

In the R.F. band with $54 \mathrm{MHz}$ channel bandwidth, an LNA with just a single signal path between 2 to $6 \mathrm{GHz}$ was studied [25]. Voltage feedback in the common-gate LNA was employed. For each R.F. band, the LNA input matching was reconfigured by making adjustments to the load network of the resonant frequency. Park reported that a one-shot tuning circuit automatically tuned the active R.C. channel selection filter's frequency characteristics with R-2R ladder. It is known as the source to the LNA will degenerate the LNA. Due to the use of the narrowband LNA architecture, its input matching network's narrowband frequency characteristic was not easy to reconfigure. The receive path showed a 4.6 to $5.6 \mathrm{~dB}$ noise figure when using $75 \mathrm{~mA}$ from a $1.8 \mathrm{~V}$ supply. This work aimed to provide continuous connection of wireless data networks that support WiBro, WiMAX as well as IEEE $802.11-\mathrm{b} / \mathrm{g} / \mathrm{n}$. The output gain of cascaded LNA reached $23 \mathrm{~dB}$. Using the $\mathrm{R}-2 \mathrm{R}$ ladder network led to a high noise level approximated at $5.6 \mathrm{~dB}$. The noise figure can be reduced by avoiding the use of resistive networks for the LNA.

In [26] proposed an LNA wideband based on current reuse the configuration of a cascade. By using resistive shunt-shunt feedback along with a parallel L.C. load, the wideband input impedance matching has been achieved to equal the input network of two parallel RLC branches. The bandwidth achieved was 7.5 $\mathrm{GHz}$. The use of resistive shunt feedback as an input impedance matching showed that a single-stage LNA produced a very high noise figure of $4.24 \mathrm{~dB}$.

The analysis of simultaneous noise and impedance matching conditions for an amplifier in a common source [27] rely on the full hybrid pi model, noise parameters of the transistor were derived. Together with an L.C. ladder matching network, with include inductive and capacitive feedback, a double reactive feedback circuit was suggested where the prior utilization of the transistor parasitic gate-to-drain capacitance. In contrast, the latter made by pairing transformer. The frequency range was between 3 to $11 \mathrm{GHz}$. The cascaded and cascoded LNA achieved $10 \mathrm{~dB}$ of energy gain and $4.5 \mathrm{~dB}$ of noise figure. The analysis and the method reported made the equation quite complicated, causing the effects of the optimize impedance on the device and the correlation of equivalent noise sources confusing. The passive device input impedance contributed to the high noise figure in series with an input port that had an input referred to a noise source.

A low-power full LNA was examined by [28] for ultra-wideband applications. This research aimed to achieve the ultra-wide bandwidth of the receivers-the frequency range around $3.1 \mathrm{GHz}$ to $10.6 \mathrm{GHz}$. Current reuse design has been used to reduce energy usage. The input resistance of $50 \mathrm{Ohm}$ was achieved deprived of any extra input matching network through the use of an input standard gate stage. Through cascading the output common drain stage, the output matching was obtained. The reported power gain was $9.7 \mathrm{~dB}$, and the noise figure was $7 \mathrm{~dB}$. As reported, even with an energy usage of $12 \mathrm{~mW}$ and $1.5 \mathrm{~V}$ of supply voltage, the cascoded LNA gain was still low.

A cascoded LNA with high-gain, low noise used a T-matching network usable to wireless applications has been illustrated by [29]. The amp employs the FHX76LP low noise super HEMT FET. The LNA built by employed a T-matching network consisting of a reactive lump component at the input/output terminal. The cascode of the LNA generated an $18.5 \mathrm{~dB}$ of gain and a $1.30 \mathrm{~dB}$ of noise figure. The input reflection (S11) and the output return loss (S22) are $-11.5 \mathrm{~dB}$ and $-12.3 \mathrm{~dB}$, correspondingly. The reported amplification has a bandwidth of $1.4 \mathrm{GHz}$. The sensitivity of the input matches the IEEE 802.16 specifications. The amplifier gain is high, and compared to other researchers, the noise figure is low. 
A wideband LNA with resistive feedback depends on a configuration of the cascade was reported [30]. By using the shunt-shunt feedback resistor, the input impedance matching with the combination of a preceding pi matching network was achieved. A post cascoded inductor was used to obtain the wideband gain respond, inserted between the cascoded transistor's output and the shunt-shunt resistive feedback network's input to boost the gain. The LNA achieved $9.6 \mathrm{~dB}$ and flat noise figure of $4.3 \mathrm{~dB}$ over a range of the frequency 1.6-28 GHz. As four spiral inductors had been used, the LNA topology with twofold RLC branch input matching network had the drawback of occupying a wide scale. The suggested wideband LNA is designed with a shunt-shunt feedback resistor following the previous pi matching network. They concluded that one of the best noise figure flatness exhibited in the wideband LNA. Results show the recommended LNA topology was highly adequate for low cost and high-performance LNA wideband. However, the amplifier's gain is low, the noise figure is still large, the frequency is too broad, and the size is big.

A low-voltage monolithic LNA cascode was designed by [31] utilizing 0.18-um CMOS technology. This LNA cascode is developed as coupled cascaded phases for low voltage applications that differ from the stacked threshold power source topology of the conservative LNA cascode. To lessen the overall power dissipation when the R.F. performance is not affected, the present occupation is decreased by lowering the second NMOS channel width. The entire circuit employed the TSMC 0.18-um CMOS technology. The measured findings demonstrate a gain of $10.7 \mathrm{~dB}$ gain and a $2.6 \mathrm{~dB}$ noise figure at a frequency of $5.4 \mathrm{GHz}$. The IIP3 is approximately $2.3 \mathrm{dBm}$. The voltage source was $0.7 \mathrm{~V}$, while the total energy dissipation is 6.3 $\mathrm{mW}$. So far, the cascode and cascaded LNA techniques were introduced, but the gain and noise figure not sufficiently.

A low-power LNA of 0.08-7 GHz design employing 0.18 $\mu \mathrm{m}$ CMOS technology has been presented by [32]. The wideband LNA design could be deployed using the T-coil network as a high-level bandwidth expansion filter. This method is integrating the design of an LNA input matching and output peaking networks. The transistors' intrinsic capacitances are used to extend the bandwidth of as part of the wideband structure. By using the suggested topology, a wideband LNA with a $0.08 \mathrm{GHz}-7 \mathrm{GHz}$ bandwidth, a noise figure of $6 \mathrm{~dB}(\mathrm{~min})$, and a maximum $18 \mathrm{~dB}$ gain was obtained. The wideband LNA total power usage from the $1.8 \mathrm{~V}$ energy supply is $4.5 \mathrm{~mW}$. This type of LNA wideband was implemented using $0.18 \mu \mathrm{m}$ CMOS technology. The overall performance is suitable for WiMAX 802.16 standard, but the noise figure is relatively high.

In [33] identified a $5.8 \mathrm{GHz}$ front-end with low noise and low power R.F. a dedicated short range communication (DSRC). The R.F. front-end consists of one to two-level differential LNA and a Gilbert down-conversion mixer. It was fabricated using a $0.13 \mu \mathrm{m}$ CMOS process and developed a supply voltage of $7.3 \mathrm{~mA}$ out of a $1.2 \mathrm{~V}$. It has been shown that the power gain of $40 \mathrm{~dB}$ and a noise figure is less than $4.5 \mathrm{~dB}$ over the whole DSRC band. A single-to-differential LNA with capacitive through doubled pair is suggested to get rid of the external balun, and the tuning circuit was $5.8 \mathrm{GHz}$ L.C. load. Therefore, this research is using the single to differential two stages LNA. The gain reported is $40 \mathrm{~dB}$ and acceptable for WiMAX, but the noise figure is relatively high.

A tunable low-noise amplifier (LNA) has been developed by [34]. The LNA's operation bands can be varied between $2.4 \mathrm{GHz}$ and $5.8 \mathrm{GHz}$ by controlling a PIN diode in the output matching network. At the PIN diode's forward bias state, the LNA operates at $2.4 \mathrm{GHz}$, the measured gain is $16 \mathrm{~dB}$, and the noise figure is below $0.6 \mathrm{~dB}$ within a bandwidth of $100 \mathrm{MHz}$. At the reverse bias state of the PIN diode, the LNA works at $5.8 \mathrm{GHz}$, the measured gain is $9.7 \mathrm{~dB}$, and the noise figure is below $1.7 \mathrm{~dB}$ within a bandwidth of $200 \mathrm{MHz}$. Compared with the wideband LNA covering $2.4 \mathrm{GHz}$ and $5.8 \mathrm{GHz}$ bands, efficient improvement in gain and noise figure is observed.

In [35] mainly investigated the simultaneous of the LNA several-band for WLAN and WiMAX applications inclusive of $2.4 \mathrm{GHz}-2.7 \mathrm{GHz}, 3.3 \mathrm{GHz}-3.8 \mathrm{GHz}$, and $5.1 \mathrm{GHz}-5.9 \mathrm{GHz}$ is. It comprised of dual cascaded common-source phases, utilizing stepped-impedance transformers and series as well as shunt feedback tactics to achieve great return loss, low noise, and high linearity concurrently. The findings revealed that the specification of LNA a return loss of $-12 \mathrm{~dB}$ input and output, a gain of $21 \mathrm{~dB}$, and a $2 \mathrm{~dB}$ of noise figure throughout the three state-of-the-art operating bands among the counterparts.

A 3.2-9.7 GHz low power of LNA with good stop-band dismissal by $0.18 \mu \mathrm{m}$ CMOS technology has been classified by [36]. A passive band-pass filter achieved rejection of the high stop-band with 3 finite transmittance zeros (at the common-gate LNA input terminal), one in the low-frequency band ( $\omega z 1=$ $0.9 \mathrm{GHz})$ and $\omega z 3$ and $\omega z 5$ at the high-frequencies stop-band. The active notch filter introduces other lowfrequency stop-band conveyance zero $(\omega \mathrm{z} 2)$ at $2.4 \mathrm{GHz}$ in the output terminal of LNA. An LNA consumer $4.68 \mathrm{~mW}$ and attains input reflection loss $\mathrm{S}_{11}$ of -10 to $-39.5 \mathrm{~dB}$, power gain $\mathrm{S}_{21}$ of $9.3 \pm 1.5 \mathrm{~dB}$, and a standard noise figure of $6 \mathrm{~dB} 3.2-9.7 \mathrm{GHz}$ band. In comparison, for $0.9 \mathrm{GHz}, 1.8 \mathrm{GHz}, 2.4 \mathrm{GHz}, 17.6 \mathrm{GHz}$ and 19.5 GHz frequencies, stop-band refusal is better compare to $21.6 \mathrm{~dB}$ with $53.3 \mathrm{~dB}, 26.4 \mathrm{~dB}, 26.5 \mathrm{~dB}, 60 \mathrm{~dB}$ 
and $59.5 \mathrm{~dB}$ in each instance. This research achieved a maximum gain is $10.8 \mathrm{~dB}$, and the noise figure is very high of $6 \mathrm{~dB}$.

The architecture and analysis of a 0.7-9 GHz CMOS Broadband High-Gain LNA for multi-band have been emphasized by [37]. The LNA was depended on the self-biased resistive-feedback topology. LNA broadband deployed a shunt-peaking inductor and the inductor within the feedback circle to expand the bandwidth. The shunt-peaking inductor with PMOSFET is selected as the load to enhance the gain whilst holding high frequencies low noise. Both diodes are placed to safeguard the input devices gate in contradiction of Electro-Static Discharge (ESD). LNA was produced in SMIC $0.13-\mu \mathrm{m}$ process. The maximum gain reported is $28.3 \mathrm{~dB}$, and the low noise figure is $3.38 \mathrm{~dB}$ with IIP3 of $-11 \mathrm{dBm}$ while consuming $17.8 \mathrm{~mA}$ from a $1.2 \mathrm{~V}$ supply. This research is quite similar to our design. Therefore, the gain and noise figure of overall results still need to be improved.

Using a feedback circuit, Lee et al. [38] managed to design an LNA with $5.2 \mathrm{GHz}$ in the baseband signal frequency. The authors implement two-stage LNA relied on cascade topology with TSMC CMOS $0.18 \mu \mathrm{m}$ technology. The authors designed the feedback circuit comprised of 7 functional blocks with minimal power usage using the circuit's storage in the feedback circuit store, former magnitude, and dodging unnecessary LNA energy consumption. Authors stimulated LNA's performance includes gain, IIP3, noise figure, constancy, and energy usage. Under $1.8 \mathrm{~V}$ power supply, the D.C power of the LNA variable gain consumed 5.68-6.75 $\mathrm{mW}$. The LNA front end with a feedback circuit, in this case, has obtained variable gains between $11.39 \mathrm{~dB}$ and $22.74 \mathrm{~dB}$, with tremendous noise efficiency although in a $3 \mathrm{~dB}$ high gain mode.

In [39], the authors introduced a fully integrated TSMC $0.18 \mu \mathrm{m}$ CMOS of two-stage CS-CS LNA circuit topology centred at $5.4 \mathrm{GHz}$. The present reuse method was implemented to create the main amplifier and using the resonant circuit, LNA is adjusted to that specific frequency. The matching used a parallel mixture of two-stage L.C. elements acts as a filter to reach good input matching and low noise figure. Authors construct the LNA design using a common source (C.S.) due to low-cost power but providing high gain, low noise, and high stability for targeted frequency range. The maximum gain achieved of $5.4 \mathrm{GHz}$ is $12.554 \mathrm{~dB}$ with minimal noise figure $0.423 \mathrm{~dB}$ over $100 \mathrm{MHz}$ bandwidth. The input reflection coefficient $\left(S_{11}\right)$ is $-23.847 \mathrm{~dB}$, output reflection coefficient $\left(S_{22}\right)$ is $-17.479 \mathrm{~dB}$, contrary isolation $\left(S_{12}\right)$ is $-20.458 \mathrm{~dB}$ and stability factor is 1.425 . The consumption of power is lower with a voltage source of $1.2 \mathrm{~V}$ and the recommended LNA used in wireless and satellite communication applications.

Khosravi et al. [40] developed a 2.4/5.2 GHz of LNA with parallel twofold-band, which can be used by Advanced Designed System (ADS) for WLAN applications using R.F-TSMC $0.18 \mu$ m CMOS technology. The authors chose to apply LNA wideband and notch filters to employ the current-reused method to decrease energy usage and offer flat gain across a wide bandwidth. The authors use notch filters at the first phase output to have the lowest impact at the targeted frequency band, and the twofold band range responds shaped at phase 2 input of the wideband LNA. Uses of a power source of $1.8 \mathrm{~V}$ have an energy usage of 2.25 $\mathrm{mW}$. Proposed LNA taking consideration of gain, input matching impedance, and noise figure of both bands. At $2.4 \mathrm{GHz}$, LNA achieved a $1.8 \mathrm{~dB}$ noise figure, a $15.9 \mathrm{~dB}$ power gain $\left(S_{21}\right)$ and $-14 \mathrm{~dB}$ an input return loss $\left(S_{11}\right)$. Meanwhile, at $5.2 \mathrm{GHz}$, it features a noise figure of $2.7 \mathrm{~dB}$, a $14.3 \mathrm{~dB}$ power gain $\left(S_{21}\right)$ and an input return loss $\left(S_{11}\right)$ of $-12.8 \mathrm{~dB}$. The suggested double-band LNA is therefore ideal for low-energy applications in multiple bands of receiver's WLAN.

In [41], proposed a $5 \mathrm{GHz} 0.18 \mu \mathrm{m}$ CMOS LNA involved in cascode topology paired with floatingbody transistors and high-Q passives on the SOI substrate to note noise figure and superior linearity efficiency between receiver and antenna. The author used an inductive matching element, which a grouping of bond wires and on-chip inductors. This LNA achieves gain $\left(S_{21}\right)$ of $11.0 \mathrm{~dB}$, an input return loss $\left(S_{11}\right)$ $-33 \mathrm{~dB}$, a noise figure of $0.95 \mathrm{~dB}$, and an IIP3 of $5 \mathrm{dBm}$ at $5 \mathrm{GHz}$ with the energy usage of $12 \mathrm{~mW}$. This research can support 802.11a WLAN applications. The effect of SOI body-contact on the performance of LNA R.F was defined and connected to strengthened circuit intermodulation performance.

\section{DISCUSSIONS}

Table 2(a) and (b) summarizes overall of LNA designs and architectures. The table illustrates LNA designs operating frequency, total gain, entire noise figure, and bandwidth. For single-stage LNA design, the highest gain achieved is $23 \mathrm{~dB}$ by [25], and the best noise figure obtained is 1.3 by [29]. While, for cascode LNA design, the highest gain achieved is $18.5 \mathrm{~dB}$, and the lowest noise figure reported is $1.3 \mathrm{~dB}$ by [29].

However, for the two stages LNA or cascaded design, the highest gain achieved is $40 \mathrm{~dB}$ by [33], and the best noise figure has been reported of $2 \mathrm{~dB}$ by Angelo [24]. Most of the gains displayed in the table are way below the targeted value of $50 \mathrm{~dB}$. Due to this reason, the cascode with feedback or cascaded LNA techniques should be introduced and implemented. 
Table 2. LNA designs and architectures, (a) summary of low noise amplifiers review for (5-5.8 GHz) frequencies

\begin{tabular}{|c|c|c|c|c|c|}
\hline Published work & Architecture of LNA & Freq. (GHz) & Gain $(\mathrm{dB})$ & N.F. (dB) & B.W.(MHz) \\
\hline$[16]$ & Single Stage & 5.0 & 22.3 & 2.6 & NS \\
\hline [17] & Single Stage Cascode & 5.8 & 12.1 & 4.5 & NS \\
\hline [21] & Two-Stage & 5.0 & 21.0 & 2.6 & NS \\
\hline$[22]$ & Single Stage & 5.6 & 17.1 & 8.7 & NS \\
\hline [23] & Single Stage Cascode & 5.5 & 10.2 & 3.02 & NS \\
\hline [24] & Folded & 5.8 & 13.79 & 1.7 & NS \\
\hline [26] & Single Stage & 5 & 12.3 & 4.2 & NS \\
\hline [29] & Single Cascode & 5.8 & 18.5 & 1.3 & NS \\
\hline [31] & Two-Stage & 5.4 & 10.7 & 2.6 & NS \\
\hline [33] & Two-Stage & 5.8 & 40 & 4.5 & NS \\
\hline
\end{tabular}

Table 2. LNA designs and architectures (b) summary of LNA review for $(0.7-10.6 \mathrm{GHz})$ frequencies

\begin{tabular}{|c|c|c|c|c|c|}
\hline Published Works & Architecture of LNA & Freq. (GHz) & Gain $(\mathrm{dB})$ & N.F. (dB) & B.W. (MHz) \\
\hline$[14]$ & Single Stage Cascode & $2.3-5.9$ & 13 & 3 & 3600 \\
\hline [15] & Single Stage & $3.1-10.6$ & 6.0 & 5.0 & 7500 \\
\hline [18] & Single Stage Cascode & $2-6$ & 16.4 & 4.1 & 4000 \\
\hline [19] & Single Stage Cascode & $3-5$ & 12.7 & 4.5 & 2000 \\
\hline [20] & Single Stage Cascode & $2.3-7$ & 16.5 & $3.4-6.7$ & 4700 \\
\hline [25] & Single Stage & $2-6$ & 23.0 & 5.6 & 4000 \\
\hline [27] & Single Stage & 3-11 & 10.0 & 4.5 & 8000 \\
\hline [28] & Single Stage & $3.1-10.6$ & 9.7 & 7.0 & 7700 \\
\hline [30] & Single Stage Cascode & $1.6-28$ & 9.6 & 4.3 & 26000 \\
\hline [32] & Single Stage Cascode & $0.08-7$ & 18 & 5 & 6980 \\
\hline [34] & Single Stage & $2.4-5.9$ & $9.7-16$ & $0.6-1.7$ & 3400 \\
\hline [35] & Two-Stage & $2.4-5.8$ & 21 & 2 & 3400 \\
\hline [36] & Single Stage & $3.2-9.7$ & 9.3 & 6 & 6500 \\
\hline [37] & $\begin{array}{l}\text { Cascode-cascaded } \\
\text { 3-Stage }\end{array}$ & $0.7-9$ & 28.3 & 3.38 & 8300 \\
\hline [38] & Two-stage LNA cascade & 5.2 & $11.39-22.74$ & 3 & NS \\
\hline [39] & Two-stage CS-CS & 5.4 & 12.544 & 0.423 & NS \\
\hline [40] & $\begin{array}{c}\text { Dual-band LNA of current-reuse } \\
\text { technique }\end{array}$ & $2.4 / 5.2$ & $\begin{array}{l}15.9 \\
14.3\end{array}$ & $\begin{array}{l}1.8 \\
2.7\end{array}$ & NS \\
\hline [41] & Inductive degenerated cascode & 5 & 11 & 0.9 & NS \\
\hline
\end{tabular}

\section{CONCLUSION}

The wireless broadband communications system is global interoperability in microwave access for urban areas. The two significant extensions of 802.16 are $802.16 \mathrm{~d}$ that define the fixed and $802.16 \mathrm{e}$ for the mobile. The modern communications system is based on R.F conveyance is one of the most significant examples of this challenging demand. LNA is a crucial section of the overall receiver system. It offers the required amplifier gain while adding the least noise to meet the essential SNR before the baseband signal is processed. The design of LNA in this research is for the application of WiMAX. Due to the capabilities and increasingly popular of the DCR, this LNA has to reside in a DCR environment. The LNA front-end receiver is the most crucial part of the receiver because it determines its overall performance. Identifying a suitable design and topology for the LNA is essential. The LNA is supposed to offer high gain, low noise, wideband, and high input/output isolation.

\section{ACKNOWLEDGEMENTS}

The authors wish to thank all those involved in this study for their encouragement and contribution, especially the Malaysia Ministry of Education, to fund the FRGS grants (2019-0015-104-02).

\section{REFERENCES}

[1] Ruey-Lue Wang, Shih-Chih Chen, Cheng-Lin Huang, Chien-Hsuan Lie, Yi-Shu Lin, "A2-6GHz Current-Reused LNA with Transformer-type Inductors," Asia-Pacific Microwave Conference, 2008, pp. 1-4, doi: 10.1109/APMC.2008.4957868.

[2] L.E. Frenzel., "Principles of Electronic Communication Systems," Third Edition, 2008.

[3] Dorra Ayadi, et al., "System Level Design of Radio Frequency Receiver for IEEE 802.16 Standard," 3rd International Design and Test Workshop, pp. 82-86, 2009, doi: 10.1109/IDT.2008.4802471. 
[4] IEEE Computer Society and IEEE Microwave Theory Technique and Society (2004) Part 16 Air Interface For Fix Broadband Wireless System, IEEE Standard 802.16, 2005, doi: 10.1109/IEEESTD.2005.97973.

[5] Hung Y.J., Jyh, C.C., and Ch, CL, "WLAN Standards: Potentials," IEEE, vol. 22, no. 4, pp. 16-22, 2003, doi: 10.1109/MP.2003.1238688.

[6] International Telecommunication Union, "Measuring Digital Development Facts and Figures 2019," Geneva: ITU, 2019.

[7] Da-Rong Huang, Shiau-Wen Kao, and Yi-Hsin Pang, "A Wimax Receiver With Variable Bandwidth of 2.5-20 Mhz and 93 dB Dynamic Gain Rang in 0.13um CMOS Process," IEEE Radio Frequency Integrated Circuits (RFIC) Symposium, 2007, doi: 10.1109/RFIC.2007.380903.

[8] A. R. Behzad, et al., "A 5-GHz Direct-Conversion CMOS Transceiver Utilizing Automatic Frequency Control for the IEEE 802.11a wireless LAN standard," IEEE Journal of Solid-State Circuits, vol. 38, no. 12, pp. 2209-2220, Dec. 2003, doi: 10.1109/JSSC.2003.819085.

[9] Norlaili, "Development of inductively Degenerated LNA for W-CDMA," PhD. The thesis of Universiti Sains Malaysia, 2008

[10] Machael Steer, "Microwave and R.F. Design,” A System Approach International Edition, 2010.

[11] Othman A.R., et al., "High Gain Cascaded Low Noise Amplifier Using T-Matching Network," Journal of Telecommunication, Electronic and Computer Engineering (JTEC), vol. 2, no. 1, pp. 63-69, 2010.

[12] M. Ismail, and C. Garuda, "A multi-band CMOS RF Front-end for 4G WiMAX and WLAN Applications," IEEE International Symposium on Circuits and Systems, 2006, pp. 4, doi: 10.1109/ISCAS.2006.1693268.

[13] Kai, C., Inder, B. and Vijay, N., "R.F. and Microwave Circuit and Component Design for Wireless Systems," Third Avenue, NY: John Wiley \& Sons, Inc, 2002.

[14] M. B. Amor, M. Loulou, and D. Pasquut., "A wideband CMOS LNA Design for WiMAX Application," 4th European Conference on Circuits and Systems for Communications, 2008 pp. 93-96.

[15] Chirala, M. Guan, K.X. and Nguyen, C., "Integrated Multilayer On-Chip Inductors for Compact CMOS RFICs and Their Use in a Miniature," IEEE transactions on microwave theory and techniques, vol. 56, no. 8, pp. 1783-1789, 2008, doi: 10.1109/TMTT.2008.926541.

[16] Vitzilaios, G. Papananos, Y. and Theodoratos. G., "A 1-V 5-GHz CMOS Multiple Magnetic Feedback Receiver Front-End," IEEE Transactions on Microwave Theory and Techniques, vol. 56, pp. 3049-3052, 2008, doi: 10.1109/TMTT.2008.921752.

[17] M. Pourakbar, P. Langari, M. Dousti, F. Temcamani, B. Dracressoniere, J. L. Gautier, "A low voltage low noise

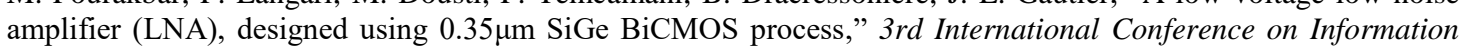
and Communication Technologies: From Theory to Applications, 2008.

[18] Man Long Her, Hao-Chih Hsu, Hsin-Hung Lin, Tseng-Hsow Yuan, and Shun-Ping Chan, "Design and Implementation of LNA for 2 to6 GHz WiMAX System," Proceedings of the 15th Asia-Pacific Conference on Communications (APCC), 2009, pp. 426-429, doi: 10.1109/APCC.2009.5375600.

[19] S.K. Wong and F.K. Fung., "Design of 3 to 5 GHz CMOS Low Noise Amplifier for Ultra-Wideband (UWB)," System Progress in Electromagnetic Research C, vol. 9, pp. 25-34, 2009, doi: http: 10.2528/PIERC09062202.

[20] Park et al., "A fully integrated CMOS wideband low noise amplifier (LNA) operating over 2.3-7 GHz is designed and fabricated using a $0.18 \mu \mathrm{m}$ CMOS process," Published in IEICE Transactions, 2009.

[21] Perumana, B.G. Zhan, J.H. Taylor, S.S Carlton, B.R and Laskar, J., "Resistive-Feedback CMOS Low-Noise Amplifiers for Multiband Applications," IEEE MTT 2009, vol 56, mo. 5, pp. 1218-1225, 2009, doi: 10.1109/TMTT.2008.920181.

[22] Chen, H. C., et al., "0.5-V 5.6 GHz CMOS Receiver Subsystem," IEEE Transactions on Microwave Theory and Techniques, vol. 57 no 2, pp. 329-335, 2009, doi: 10.1109/TMTT.2008.2011165.

[23] C.P. Chang, W.C. Chien, C.C. Su, and Y.H. Wang., "Linearity Improvement of Cascode CMOS LNA using a Diode Connected NMOS Transistor with a Parallel R.C. Circuit," Progress in Electromagnetic Research C, vol. 17, pp. 29-38, 2010, doi: http: 10.2528/PIERC10082411.

[24] Michael Angelo G. Lorenzo and Maria Theresa G. de Leon, "Comparison of LNA for WiMAX Applications in a Standard 90-nm CMOS Process," 12th International Conference on Computer Modeling and Simulation, 2010, pp. 642-647, doi: 10.1109/UKSIM.2010.122

[25] Park, J., Kim, S, N., Roh, Y. S., and Yoo, C., "A Direct Conversion CMOS RF Receiver Reconfigurable from 2 to 6 GHz," IEEE Transactions on Microwave Theory and Techniques, vol. 58, pp. 2326-2333, 2010, doi: 10.1109/TMTT.2010.2057173.

[26] Lin, Y.S. Chen, C.Z., Yang, H.Y. Chen, C.C. Lee, J.H. Huang, G.W. and Lu, S.S., "Analysis and design of a CMOS UWB LNA With Dual-RLC-Branch Wideband Input Matching Network," IEEE Transactions on Microwave Theory and Techniques, vol. 58, no. 2, pp. 287-309, 2010, doi: 10.1109/TMTT.2009.2037863.

[27] Chang, C.P. Chen, J.H. and Wang, Y.H., "A Fully Integrated 5 GHz Low-Voltage LNA Using Forward Body Bias Technology," IEEE Transactions on Microwave Theory and Techniques, vol. 19, no. 3, pp 176-178, 2010, doi: 10.1109/LMWC.2009.2013745.

[28] Ro-Min W., Chun-Yu L., Po-Cheng Lin, "A low-power full-band low-noise amplifier (FB-LNA) for ultrawideband applications," IEEE Transactions on Microwave Theory and Techniques, vol. 58, no. 8, pp. 2077-2083, 2010, doi: 10.1109/TMTT.2010.2052404.

[29] Othman A.R, et al, "High Gain, Low Noise Cascode LNA Using T-Matching Network for Wireless Applications," IEEE Asia-Pacific Conference on Applied Electromagnetics (APACE), 2012, pp. 383-387, doi: 10.1109/APACE.2012.6457699. 
[30] Hsien-Ku Chen, Yo-Sheng Lin, and Shey-Shi Lu, "Analysis and Design of a 1.6-28 GHz Compact Wideband LNA in 90-nm CMOS Using a $\pi$-Match Input Network," IEEE Transactions on Microwave Theory and Techniques, vol. 58, no. 8, pp. 2092-2104, 2010, doi: 10.1109/TMTT.2010.2052406.

[31] Baohong Liu and Junfa Mao, "Design of a 0.5 V CMOS Cascode Low Noise Amplifier for Multi-Gigahertz Applications," Journal of Semiconductor, vol. 33, no. 1, 2012.

[32] J. Chaudhari, Rachna J. and S. Oza., "A 0.08-7 GHz low power low noise amplifier design using $0.18 \mu \mathrm{m}$ CMOS Technology," Int. Journal Computer Science and Emerging Technologies, vol. 2, no. 4, pp. 513-519, 2011.

[33] Jaeyi Choi, Shin-Hyouk Seo, Hyunwou Moon, and llku Nam, "A low Noise and Low Power R.F. Front-end for 5.8 GHz DSRC Receiver in $0.13 \mu \mathrm{m}$ CMOS," Journal of Semiconductor Technology and Science, vol. 11, no. 1, pp. 59-64, 2011, doi: 10.5573/JSTS.2011.11.1.059.

[34] G.L. Ning, Z.Y. Lei, L.J. Zhang, R. Zou, and L. Shao, "Design of Concurrent Low Noise amplifier for Multi-Band Applications," Progress in Electromagnetics Research C, vol. 22, pp. 165-178, 2011.

[35] Dezhou Hou, Wei Hong, and K. Wu., "A 2.4 GHz and 5.8 GHz Tunable Low Noise Amplifier Using PIN Diode," CJMW Proceedings, 2011.

[36] Jin-Fa Chang, Yo-Sheng Lin, Jen-How Lee, and Chien-Chin Wang, "A low-Power 3.2-9.7 GHz Ultra-Wideband Low Noise Amplifier with Excellent Stop-band Rejection Using $0.18 \mu \mathrm{m}$ CMOS Technology," Microwave and Optical Technology Letters, vol. 54, no. 5, pp. 1253-1261, 2012.

[37] Youming Z. Fengyi H, Xusheng Tang, Dawei Z., "The design and analysis of a 0.7-9 GHz CMOS Broadband High-Gain Low Noise Amplifier for multi-band," 2012 International Conference on Microwave and Millimeter Wave Technology (ICMMT), vol. 1, pp. 1-4, 2012, doi: 10.1109/ICMMT.2012.6229983.

[38] W. Lee, J. Lee and J. Jeong, "Design of Variable Gain Low Noise Amplifier Using Feedback Circuit with Memory Circuits For 5.2 GHz Band," Analog Integrated Circuits and Signal Processing, vol. 68, no. 1, pp. 43-50, 2012.

[39] S. Udaya Shankar, M. Davidson K. D., "Design and Performance Measure of 5.4 GHz CMOS Low Noise Amplifier using Current Reuse Technique in $0.18 \mu \mathrm{m}$ Technology," Procedia Computer Science, vol. 47, pp. 135-143, 2015.

[40] H. Khosravi, S. Zandian, A. Bijari and N. Kandalaft., "A Low Power, High Gain 2.4/5.2 GHz Concurrent DualBand Low Noise Amplifier," IEEE 9th Annual Computing and Communication Workshop and Conference (CCWC), 2019, pp. 788-792, doi: 10.1109/CCWC.2019.8666621.

[41] Anuj Madan, Michael J. M., Christophe M., William V. and John D. C., "A 5 GHz 0.95 dB N.F. Highly Linear Cascode Floating-Body LNA in $180 \mathrm{~nm}$ SOI CMOS Technology," IEEE Microwave and Wireless Components Letters, vol. 22, no. 4, pp. 200-202, 2012, doi: 10.1109/LMWC.2012.2187882.

\section{BIOGRAPHIES OF AUTHORS}
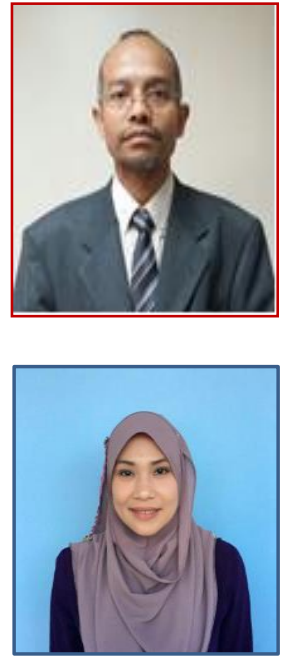

Abu Bakar Ibrahim is an Associate Professor in the Computing Department, Faculty of Arts, Computing and Creative Industry at Sultan Idris Education University, Malaysia. He is received a B.Sc. in Electrical Engineering and a Master's Degree from Universiti Teknologi Malaysia (UTM) in 1998 and 2000, respectively. In 2013, he received a PhD from Universiti Teknikal Malaysia Melaka (UTeM) in Electronic Engineering (Communication). He has professional teaching experience in Low Noise Amplifier (LNA) development, R.F. Communication System, Instructional Technology, Engineering Mathematics, Wireless Communication, and Engineering Education. In the direction of enhancing innovative creativity in Engineering, Science \& Technology, he has built self-assurance and interest in research and teaching fields.

Che Zalina Zulkifli is Associate Professor of the Faculty of Arts, Computing \& Creative Industry in the Sultan Idris Education University, Malaysia. As an Academia, she has more two decades of expert teaching experience and actively engaged in Electronics \& Electrical Engineering, Information Technology, Embedded System, Industry Creative \& Networking field. Have experience as a Test Engineer in a global corporation. Her research ventures have joined forces with a global firm and government corporation to build a portfolio that contributes to innovative concepts and tangible ventures. To date, the industry has successfully taken overbuilt automation projects focusing on Sensor Monitoring, Embedded System, Software, loT, and Wireless Communication. Over a million Ringgit has generated revenue for the Institutions, primarily through the Research Grant, commercialization of innovative research products and the facilities given as a key adviser. Agricultural experience with modern innovation to expand crop production embraced high tech. She's devoted to the very wise to the recycling of green and waste reuse project. She has received numerous globally and nationally awards. She has built faith and enthusiasm in research and teaching fields to enrich innovative invention in Engineering, Science \& Technology. 


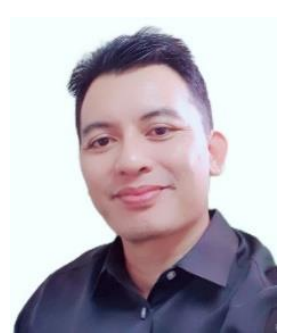

Shamsul Arrieya Ariffin is an Associate Professor in the Faculty of Art, Computing, and Creative Industries at the University of Education Sultan Idris (UPSI), Tanjong Malim, Perak, Malaysia. He is also one of the ACM members for the Malaysian Chapter and served as a Local Chapter Officer. He has served in ICT fields for more than 20 years. Initially joined UPSI, he had served with local and numerous international companies in the fields of ICT from AIG Software International, USA. For example, as Software Engineer and AIG Technology Data Center, USA as a System Engineer, while in CUA UK as an analyst programmer, NIIT India as an I.T. Trainer, and also with a Malaysian company. He earned his PhD from the Faculty of Engineering and Information Technology, University of Technology, Sydney, Australia, in Software Engineering, in 2014. His mobile learning research focuses on the bridging of the digital gap amongst the cultural and technical dimensions that ICT plays for the benefits of society. His teaching areas are Software Configuration Management, Human-Computer Interaction, and Introduction to Java Programming. His involvement with research includes the receiving of external grants such as for FRGS for "Student-Generated Activities in Mobile Learning." He has also collaborated with an external research grant from the Community Health Department, Faculty of Medicine, UKM, Malaysia, to create awareness for the public regarding community public health for student-generated activities in mobile learning. He has also won several awards for achievement from his innovation, either at the national and international levels. Confidence and interest in research and teaching have been formed to foster innovative creativity in Engineering, Science \& Technology.

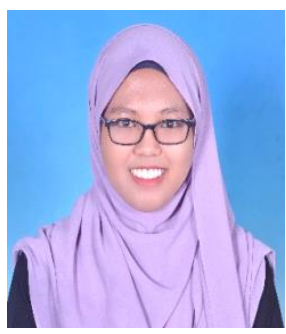

Nurul Husna Abdul Kahar is currently pursuing a Master of Engineering Technology at Sultan Idris Education University, Malaysia. She received her Bachelor's degree in Education Computer-Aided Design Technology from Sultan Idris Education University, Malaysia, in 2018. She has had a background in technology and holds keen interests in the area of teaching and engineering to assure progressive Innovation in Engineering, Science \& Technology. 